\title{
THE USE OF THE GREEN CHEMISTRY CONCEPT IN THE SYNTHESIS OF PACKAGING MATERIAL BASED ON POLYLACTIDE
}

\author{
Nevena Vukić ${ }^{1}$ (D), Tamara Erceg ${ }^{1}$ (D), Vesna Teofilović ${ }^{1}$ (D), Ljubiša Nikolić ${ }^{2}$, \\ Suzana Cakić ${ }^{2}$, Borislav Simendić ${ }^{3}$, Ivan Ristić ${ }^{1}$ iD \\ ${ }^{1}$ University of Novi Sad, Faculty of Technology, Novi Sad, Serbia \\ ${ }^{2}$ University of Niš, Faculty of Technology, Leskovac, Serbia \\ ${ }^{3}$ Higher Technical School of Professional Education, Novi Sad, Serbia
}

\begin{abstract}
A world without plastics, or synthetic polymer materials, seems unimaginable today. During the last decade, the share of synthetic polymer consumption used in packaging industry increased to $42 \%$, in relation to the total consumption of polymers. Wide use of polymer materials leads to generation of large amount of waste. Environmental pollution, as well as alarming reduction of fossil fuels have led to the implementation of the strategies for pollution control, pollution prevent, energy and resources saving. Growing awareness of global pollution consequences has rised these concerns on the level of the Green Chemistry concept. Green Chemistry is a multidisciplinary field where chemistry science and industry meets each other in order to design products and strategies for elimination of harmful substances. It is well known that the most important primary sources of feedstock for polymer materials production are fossil fuels. Increasing demand for polymers, has imposed the need for fossil fuels replacement by renewable resources for its synthesis. In this paper we have shown the implementation of the Green Chemistry principles in the synthesis of packaging material based on polylactide (PLA). Polylactide is one of the most promising polymers because of its biocompatibility, biodegradability and the fact that it can be produced from the biobased feedstocks. In accordance with modern ecological requirements, packaging material should be degradable or biodegradable and also economic. The use of PLA has a growing trend, therefore, today it takes an important place in packaging industry, especially because the properties of PLA films are comparable to standard petroleum based flexible packaging materials. The main purpose of this study was to synthese packaging material based on polylactide by microwave synthesis as a method which implement some of the Green Chemistry principles. Microwave synthesis of PLA meets requirements of biobased polymers from the aspect of energy and time saving production of this biodegradable material. The microwave-assisted synthesis of PLA provides homogenous heating of reaction mixture, significant reduction in polymerization time, decreased consumption of organic solvent and, in the same time, high molecular weight polymers.
\end{abstract}

Key words: polylactide, packaging, green chemistry, microwave synthesis

\section{INTRODUCTION}

The reducing of waste production is one of the major challenges of the present era. Polymers represent the largest segment of global waste, this leads to the problems such as recycling and decomposition of polymer materials. Also, fossil resources have been reduced and the increasing concentration of carbon dioxide in the atmosphere has focused attention on the development of biopolymer materials, such as polylactide (PLA). The production of polylactide presents numerous advantages: it can be obtained from a renewable agricultural source (like corn starch or sugar cane), it is compostable and recyclable, its production consumes quantities of carbon dioxide, it provides significant energy savings, and the physical and mechanical properties can be manipulated through the polymer architecture (Auras et al, 2004).

Among the use of polylactide in the field of electronic, textile, pharmacy and medicine, industrial production is directed to the field of packaging industry. The use of PLA in packaging, especially in food, is increasing due to biodegradability of this material because polymer packaging materials can be contaminated by biological substance and foodstuff, which makes the recycling of these materials impracticable and most of the time not economically convenient. PLA is extremely versatile and can be injection molded into plastic parts, extruded into sheet or film, foamed, thermoformed or spun into fibers and filaments. This material also provides an excellent surface for printing and graphics. The high natural surface energy combined with good ink receptivity allows PLA to be used on conventional equipment using standard printing inks. Due to its higher cost, the initial focus of polylactide as a packaging material has been in high value films, food and beverage containers, coated papers and rigid thermoforms. PLA 
may have packaging applications for a broader array of products as new and emerging production technologies lower its production costs. The use of PLA as a packaging material has increased mainly in the area of fresh products where polylactide is being used as a food packaging material for short shelf life products. PLA is also recognized as safe material for use in food packaging, but the use of this polymer as food packaging material can be limited because of the ductility, thermal and barrier properties (Arrieta et al, 2013; Martino et al, 2011). As the price for polylactide production drops and new facilities produce higher volumes of this polymer, new applications will be pursued.

It is possible to manipulate with PLA physical, mechanical and barrier properties by changing its chemical composition, and varying its molecular characteristics. It is also possible to blend polylactide with other polymers and to use nanomaterials and nanotechnologies in structuring of this material, making it a good biodegradable alternative for use in polymer packaging. If we compare PLA with other polymer packaging materials, we can noted that polylactide has lower melting $(\mathrm{Tm})$ and glass transition temperature (Tg) than poly(ethylene terephthalate) (PET) and polystyrene (PS), which make this polymer better for heat sealing and thermal processing. Polylactide is a clear, colorless thermoplastic when quenched from the melt and it is similar in many aspects to polystyrene (PS) (Auras et al, 2003; Madhavan Nampoothiri et al, 2010). But it is important to emphasize that thermal and mechanical properties of PLA are higher than the other biodegradable polyesters (polybutylene succinate - PBS, polyhydroxybutyrate - PHB and polycaprolactone - PCL).

The monomer lactic acid has two optical isomers, $L$ and $D$, resulting in polymers that can present three forms: PLLA, PDLLA and PDLA. The stereochemistry, the ratio of $L$ and $D$ isomers, influences on polylactide properties and degradability (Abdel-Rahman et al, 2011). Direct polycondensation of lactic acid gives only the low molecular weight polymer, poly(lactic acid). It is equilibrium reaction, with water as by-product, which should be removed during the synthesis, in order to get higher conversions. Removing of water during the synthesis, as well as using a coupling agent to obtain higher molecular weights makes this process longer, more complicated and more expensive. For the preparation of high molecular weight polymer, cyclic lactide is used as monomer for the ring opening polymerization (ROP) (Figure 1) (Nice et al, 2003). ROP process demands high purity of the monomer, specific catalyst and solvent. Depending on methods, it requires high temperature, high pressure or vacuum. Traditional methods of PLA synthesis require large consumption of energy, time and reagents. Polymerization in organic solvent takes place from 4 to 50 hours depending on applied mechanism, temperature, catalyst and solvent. The applied temperature ranges from 40 to even $280{ }^{\circ} \mathrm{C}$. Long polymerization time and high temperature require significant quantities of energy.

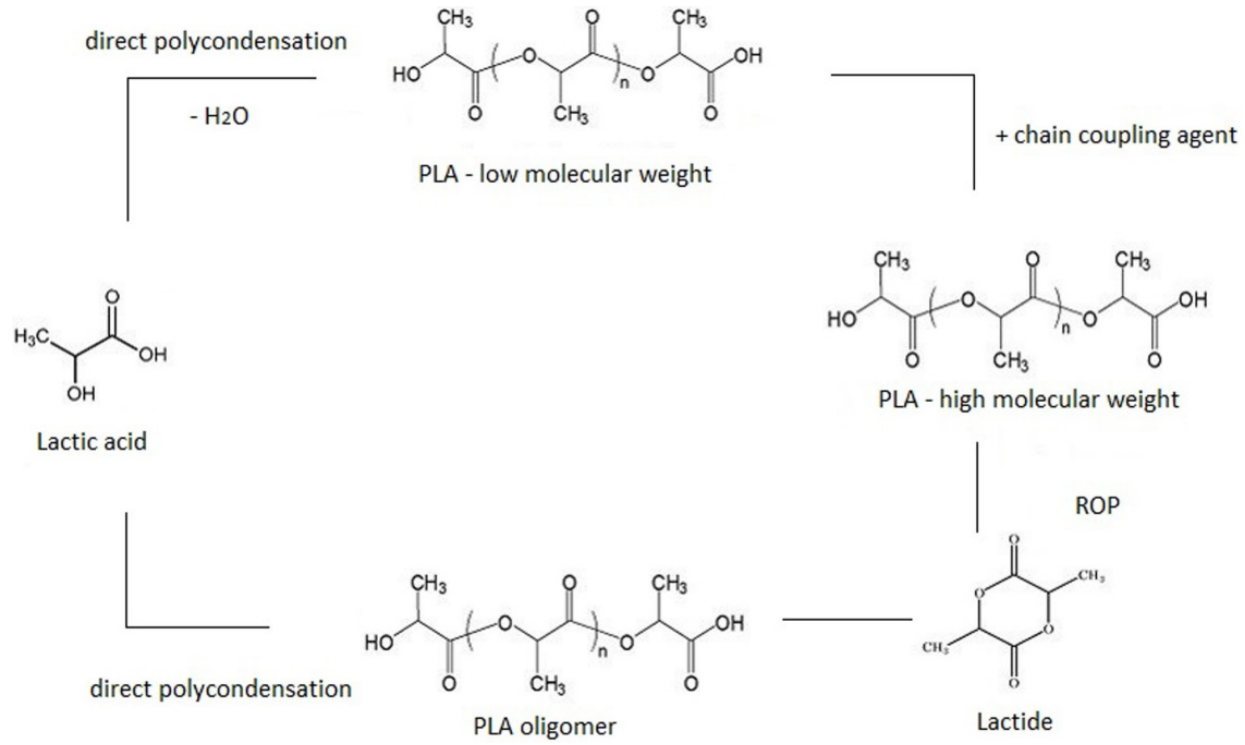

Figure 1: Synthesis of polylactide via direct polycondensation and via ROP method.

Difficulties that occur during the traditional methods of PLA synthesis can be overcome using a microwave heating as a solution which lies in the concept of Green Chemistry. The Green Chemistry concept seeks to redesign the materials that make up the basis of our society and our economy, in ways which are harmless for humans and the environment and possess intrinsic sustainability. In this concept, 
by minimizing the hazard portion of the equation, using innocuous chemicals and processes, prevention is the approach to risk reduction. Green Chemistry has been enormously successful in devising ways to reduce pollution through efficiency of materials synthesis, catalysis, and improvements in solvent technology. Alternative synthesis methods have been applied to reduce energy consumption in the industry, and biobased feedstocks are decreasing our reliance on deficit fossil resources. In Table 1 are shown Twelve Principles of Green Chemistry which are a comprehensive set of design guidelines that have guided Green Chemistry development for many years (Anastas et al, 1998).

Table 1: The Twelve principles of Green Chemistry

\begin{tabular}{|c|c|c|}
\hline $\begin{array}{l}\text { 1. Prevention } \\
\text { It is better to prevent waste than to } \\
\text { treat or clean up waste after it has } \\
\text { been created. }\end{array}$ & $\begin{array}{l}\text { 2. Atom Economy } \\
\text { Synthetic methods should be } \\
\text { designed to maximize the } \\
\text { incorporation of all materials used in } \\
\text { the process into the final product. }\end{array}$ & $\begin{array}{l}\text { 3. Less Hazardous Chemical } \\
\text { Syntheses } \\
\text { Wherever practicable, synthetic } \\
\text { methods should be designed to } \\
\text { use and generate substances } \\
\text { that possess little or no toxicity } \\
\text { to human health and the } \\
\text { environment. }\end{array}$ \\
\hline $\begin{array}{l}\text { 4. Designing Safer Chemicals } \\
\text { Chemical products should be } \\
\text { designed to effect their desired } \\
\text { function while minimizing their } \\
\text { toxicity. }\end{array}$ & $\begin{array}{l}\text { 5. Safer Solvents and Auxiliaries } \\
\text { The use of auxiliary substances (e.g., } \\
\text { solvents, separation agents, etc.) } \\
\text { should be made unnecessary } \\
\text { wherever possible and innocuous } \\
\text { when used. }\end{array}$ & $\begin{array}{l}\text { 6. Design for Energy Efficiency } \\
\text { Energy requirements of chemical } \\
\text { processes should be recognized } \\
\text { for their environmental and } \\
\text { economic impacts and should be } \\
\text { minimized. If possible, synthetic } \\
\text { methods should be conducted at } \\
\text { ambient temperature and } \\
\text { pressure. }\end{array}$ \\
\hline $\begin{array}{l}\text { 7. Use of Renewable Feedstocks } \\
\text { A raw material or feedstock should } \\
\text { be renewable rather than depleting } \\
\text { whenever technically and } \\
\text { economically practicable. }\end{array}$ & $\begin{array}{l}\text { 8. Reduce Derivatives } \\
\text { Unnecessary derivatization (use of } \\
\text { blocking groups, protection/ } \\
\text { deprotection, temporary modification } \\
\text { of physical/chemical processes) } \\
\text { should be minimized or avoided if } \\
\text { possible, because such steps require } \\
\text { additional reagents and can generate } \\
\text { waste. }\end{array}$ & $\begin{array}{l}\text { 9. Catalysis } \\
\text { Catalytic reagents (as selective as } \\
\text { possible) are superior to } \\
\text { stoichiometric reagents. }\end{array}$ \\
\hline $\begin{array}{l}\text { 10. Design for Degradation } \\
\text { Chemical products should be } \\
\text { designed so that at the end of their } \\
\text { function they break down into } \\
\text { innocuous degradation products } \\
\text { and do not persist in the } \\
\text { environment. }\end{array}$ & $\begin{array}{l}\text { 11. Real-time analysis for Pollution } \\
\text { Prevention } \\
\text { Analytical methodologies need to be } \\
\text { further developed to allow for real- } \\
\text { time, in-process monitoring and } \\
\text { control prior to the formation of } \\
\text { hazardous substances. }\end{array}$ & $\begin{array}{l}\text { 12. Inherently Safer Chemistry for } \\
\text { Accident Prevention } \\
\text { Substances and the form of a } \\
\text { substance used in a chemical } \\
\text { process should be chosen to } \\
\text { minimize the potential for } \\
\text { chemical accidents, including } \\
\text { releases, explosions, and fires. }\end{array}$ \\
\hline
\end{tabular}

Microwave heating simplifies and accelerates the reaction of polymerization of lactide that lasts only 5-30 minutes. Sensitivity of the reaction to impurities and moisture from the air is significantly reduced due to the fact that the reaction takes place very quickly, so there is no need for recrystallization of monomers or carrying out of reaction under the vacuum (Ristić et al, 2012; Nikolić et al, 2010). Homogenous heating of the whole reaction mixture and high transfer energy per unit of time result in faster polymerization rate (Nikolić et al, 2010; Singla et al, 2012). Microwave synthesis allows obtaining a high molecular weight polymer in a short time in improved yield (Nikolić et al, 2010).

In this paper is shown how we can obtain applicable packaging material whose complete life cycle is put in ecological framework by implementing some of the Green Chemistry principles in the synthesis of PLA, emphasising the aspects of saving energy and resources accomplished using microwave reactor. The synthesis of polylactide as a biobased material that degrades in natural environment, also fits into the Green Chemistry concept. 


\section{METHODS}

L-lactide (3,6-Dimethyl-1,4-dioxane-2,5-dione) and tin (II)- ethylhexanoate were supplied from SigmaAldrich. Toluene was procured from LACH-NERs.r.o. L-lactide was purificated by recrystallization with methanol and placed in evaporating dish. Catalyst, tin (II)-ethylhexanoate, was added together with toluene. After homogenization of reaction mixture, the toluene was evaporated in vacuum, at $60{ }^{\circ} \mathrm{C}$. Then the reaction mixture was closed in ampules which were put in a "Discover" focus microwave reactor, CEM Corporation, Matthews, NC, USA. Polymerization was performed at frequency of $2.45 \mathrm{GHz}$ and power of $150 \mathrm{~W}$, for 5,10 and 20 minutes.

The molecular structure of obtained samples was analysed by Fourier Transform-Infrared Spectroscopy (FTIR), using a Shimadzu M850 Model FT-IR Spectrophotometer. The scans were recorded in the range of $4000-400 \mathrm{~cm}^{-1}$.

Thermal properties of synthesized materials were investigated in nitrogen atmosphere using a TA Q20 Differential Scanning Calorimeter. Hermetically sealed aluminium pans containing around $5 \mathrm{mg}$ of samples were prepared. The scans were recorded by heating of samples from -50 to $200{ }^{\circ} \mathrm{C}$, at a rate of $10{ }^{\circ} \mathrm{C} / \mathrm{min}$. Data for melting temperature $\left(T_{\mathrm{m}}\right)$, crystallization temperature $\left(T_{c c}\right)$ and glass transition $\left(T_{g}\right)$ were recorded and are reported.

For the determination of the surface energy of the synthesized polylactide samples, the contact angle measurement was performed on the Drop Shape Analyzer DSA25 KRUSSS. The contact angle is measured using the image of a sessile drop at the points of intersection between the drop contour and the surface.

\section{RESULTS AND DISCUSSION}

Temperature and power change with reaction time were demonstrated at Figure 2. Lactide absorbs microwaves, and as a result of microwave heating and heating realised during the exothermic reaction, the temperature of reaction mixture linearly increases with the time in first $250 \mathrm{~s}$. The loop on the curve originates from the presence of both - monomer and polymer in reaction mixture, which have different ability to absorb microwaves. Monomer is more polar than polymer and, therefore, possesses greater ability to absorb microwaves. Microwave irradiation was automatically switched off after $500 \mathrm{~s}$, after reaching a temperature of $100{ }^{\circ} \mathrm{C}$. The applied power of $150 \mathrm{~W}$ at the beginning of reaction dropped to zero after reaching an appointed temperature of $100{ }^{\circ} \mathrm{C}$. After $500 \mathrm{~s}$, the power of $40 \mathrm{~W}$ was sufficient for performing the polymerization.

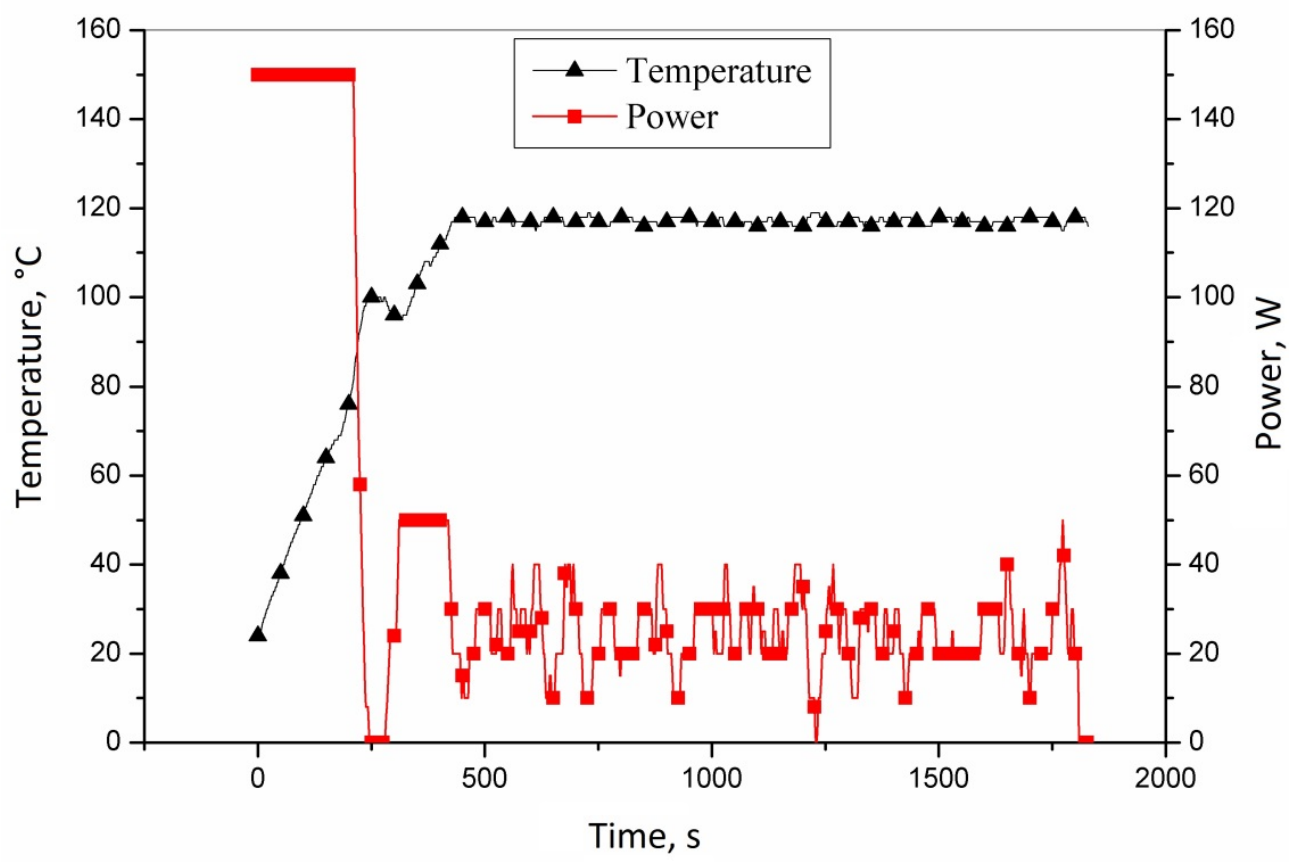

Figure 2: Temperature and microwave radiation power dependence on reaction time 
The molecular structures of synthesized polymers were confirmed by FTIR (Figure 3). The broad peak at $3485 \mathrm{~cm}^{-1}$ is attributed to the $\mathrm{O}-\mathrm{H}$ stretching. The two peaks at 2985 and $2891 \mathrm{~cm}^{-1}$ correspond to symmetric and asymmetric $-\mathrm{CH}_{2}$ stretching. Sharp peak at $1750 \mathrm{~cm}^{-1}$ is attributed to $\mathrm{C}=\mathrm{O}$ stretching vibrations. Peak at $1454 \mathrm{~cm}^{-1}$ corresponds to $-\mathrm{CH}_{2}$ bending. C-O-C stretching vibrations are detected at 1257 and $1099 \mathrm{~cm}^{-1}$.

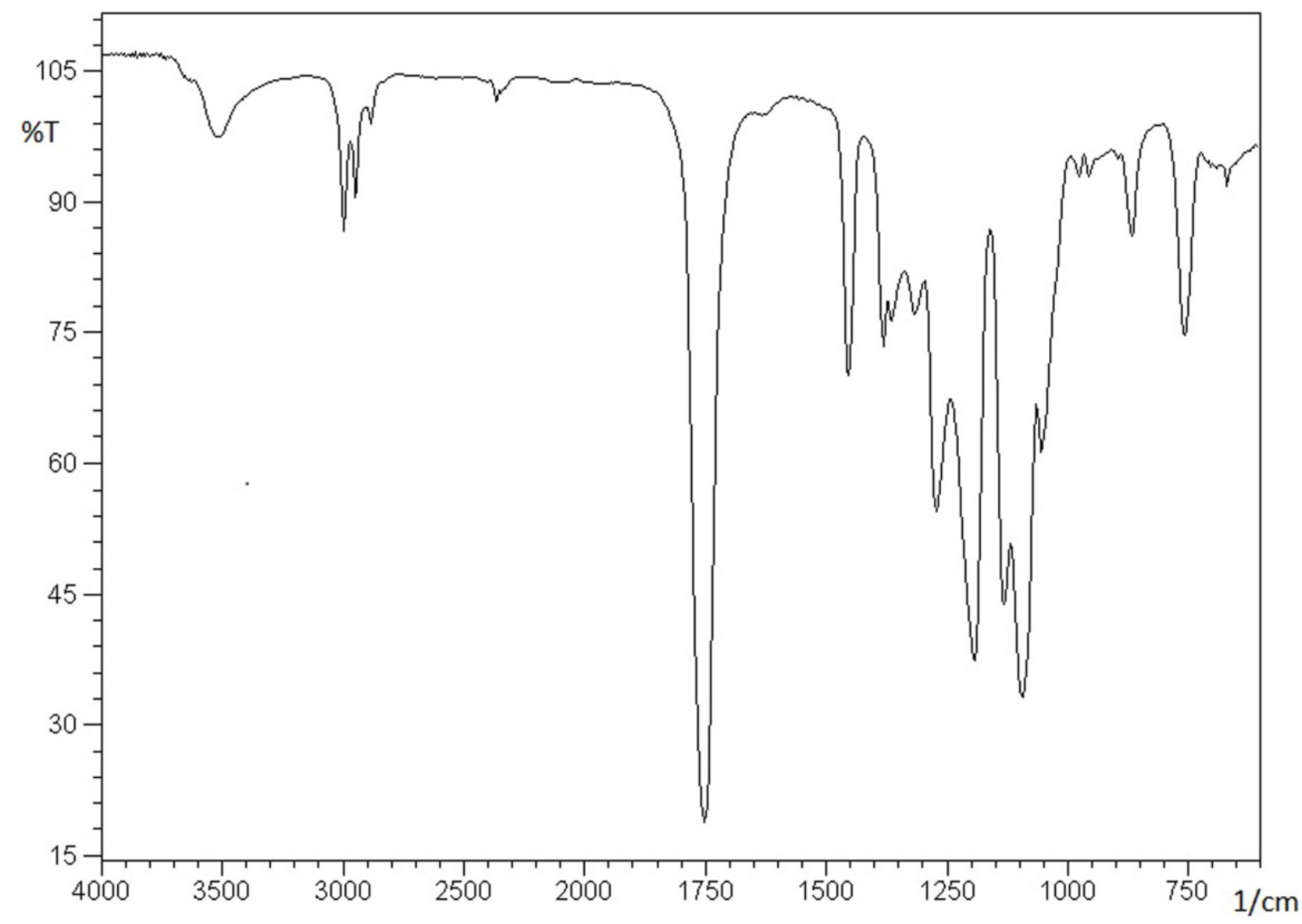

Figure 3: FTIR spectrum of polylactide.

Thermal properties of synthesized samples were analyzed by differential scanning calorimetry (DSC). Obtained results have showed that glass transition temperature $\left(T_{\mathrm{g}}\right)$ and melting temperature $\left(T_{\mathrm{m}}\right)$ values of analyzed samples increase with increasing in duration of polymerization reaction (Table 2). However, as the reaction time increases, the temperature of "cold" crystallization $\left(T_{c c}\right)$ increases, as result of higher molar mass of polymer achieved after longer reaction time.

Table 2: Thermal properties of PLA samples obtained from DSC curves.

\begin{tabular}{|c|c|c|c|c|}
\hline & Reaction time $[\mathrm{min}]$ & $\mathrm{T}_{\mathrm{g}}\left[{ }^{\circ} \mathrm{C}\right]$ & $\mathrm{T}_{\mathrm{cc}}\left[{ }^{\circ} \mathrm{C}\right]$ & $\mathrm{T}_{\mathrm{m}}\left[{ }^{\circ} \mathrm{C}\right]$ \\
\hline PLA 1 & 5 & 42 & 86 & 154 \\
\hline PLA 2 & 10 & 44 & 92 & 155 \\
\hline PLA 3 & 20 & 47 & 98 & 159 \\
\hline
\end{tabular}

Higher surface energy of packaging materials will provide more satisfactory printing properties without surface treatment. If higher surface energy is needed for processing, the surface can be treated by corona discharge. Figure 4 shows water drops recorded on the instrument for the contact angle measurement, based on which the surface energy values of the polylactide materials are calculated. The obtained surface energy values of the synthesized PLA materials are shown in the Table 3. All samples have the similar surface energy, which is satisfactory high for further processing of this material. 


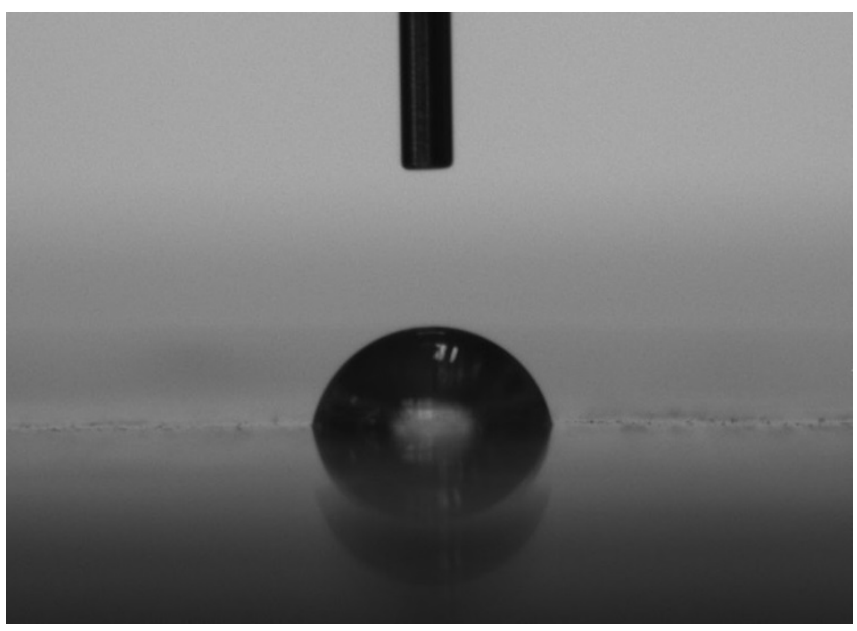

Figure 4: Water drops on synthesized polylactide material

Table 3: Surface energy of synthesized polylactide material

\begin{tabular}{|c|c|c|}
\hline Sample name & $\begin{array}{c}\text { Reaction time } \\
{[\mathrm{min}]}\end{array}$ & $\begin{array}{c}\text { Surface energy } \\
{[\mathrm{mN} / \mathrm{m}]}\end{array}$ \\
\hline PLA 1 & 5 & 36.8 \\
\hline PLA 2 & 10 & 37.4 \\
\hline PLA 3 & 20 & 37.1 \\
\hline
\end{tabular}

\section{CONCLUSIONS}

Polylactide meets many requirements as a packaging thermoplastic and is suggested as a commodity resin for general packaging applications. Over the past decade, new polymerization methods are discovered and they allow the economical production of high molecular weight PLA, and this have resulted in an expanded use of PLA for consumer goods and packaging. Because polylactide is compostable and derived from renewable sources, it has been considered as one of the solutions to alleviate solid waste disposal problems and to lessen the dependence on petroleum-based polymers for packaging materials. These facts have faced scientific community with necessity for development energy efficient process for polylactide obtaining. In accordance with the Green Chemistry concept, microwave synthesis of PLA can be applied. Microwave synthesis gives high molar weight PLA with quite regular structure in improved yield. Shorter polymerization time and reduced consumption of energy and resources accompanied with desired properties of polymer, make microwave synthesis applicable to contemporary requirements. The use of microwaves enables homogenous heating of reaction mixture, lower consumption of organic solvent and drastic reduction in polymerization time, obtaining high molecular weight polymers. In this research polylactide based materials were synthesised using microwave method and molecular structures, and thermal properties of obtained samples were investigated. Particular consideration was given to the surface energy of obtained polymer materials. The presented results confirm that microwave synthesis can be an adequate method for preparing of PLA materials which can be used for packaging applications. The answer on question how do the microwave synthesis of polylactide affects the other properties which are important for packaging materials (such as mechanical or barrier), requires further investigation.

\section{ACKNOWLEDGEMENTS}

This paper were supported by Ministry of Science and Technological Development, Republic Serbia, contract grant number III 45022. 


\section{REFERENCES}

[1] Abdel-Rahman, M. A., Tashiro, Y., Sonomoto, K.: "Lactic acid production from lignocellulose-derived sugars using lactic acid bacteria: Overview and limits", Journal of Biotechnology 156(4), 286-301, 2011. doi: 10.1016/j.jbiotec.2011.06.017.

[2] Anastas, P. T., Warner, J. C.: "Green Chemistry: Theory and Practice", (Oxford University Press: New York, 1998.), page 30.

[3] Auras, R., Harte B., Selke S.: "An Overview of Polylactides as Packaging Materials", Macromol. Biosci. 4, 835-864, 2004. doi: 10.1002/mabi.200400043.

[4] Auras, R. A., Harte B., Susan S., Hernandez R..: “Mechanical, Physical, and Barrier Properties of Poly(Lactide) Films", Journal of Plastic Film and Sheeting 19(2), 123-135, 2003. doi: 10.1177/8756087903039702.

[5] Arrieta, M. P., López, J., Ferrándiz, S., Peltzer M. A.: “Characterization of PLA - limonene blends for food packaging applications", Polymer Testing 32(4), 760-768, 2013. doi: 10.1016/j.polymertesting.2013.03.016.

[6] Madhavan Nampoothiri, K., Nair, N. R., John, R. P.: "An overview of the recent developments in polylactide (PLA) research", Bioresource Technology 101(22), 8493-8501, 2010. doi: 10.1016/j.biortech.2010.05.092.

[7] Martino, V. P., Jimenez A., Ruseckaite, R. A., Avérous, L.: "Structure and properties of clay nanobiocomposites based on poly(lactic acid) plasticized with polyadipates", Polymers for Advanced Technologies 22(12), 2206-2213, 2011. doi: 10.1002/pat.1747.

[8] Nice, G.W., Gluaser, T., Connor, E.F., Mork, A., Waymounth, R.M., Hedrick, J.L.: "In Situ Generation of Carbenes:A General and Versatile Platform for Organocatalytic Living Polymerization" Journal of the American Chemical Society, 125(10), 3046-3056, 2003. doi: 10.1021/ja021084+.

[9] Nikolić Lj., Ristić I., Adnadjević B., Nikolić V., Jovanović J., Stanković M.: "Novel Microwave-Assisted Synthesis of Poly(D,L-lactide): The Influence of Monomer/Initiator Molar Ratio on the Product Properties", Sensors 10(5), 5063-5073, 2010. doi: 10.3390/s100505063.

[10] Ristić I.S., Nikolić Lj.B., Cakić S.M., Radičević R.Ž., Pilić B.M., Budinski-Simendić J.K.: "Poli(laktid)dostignuća i perspektive“, Savremene tehnologije 1(1), 67-77, 2012.

[11] Singla P., Kaur P., Mehta R., Berek D., Upadhyay S.N.: "Ring-Opening Polymerization of Lactide Using Microwave and Conventional Heating", Procedia Chemistry 4, 179-185, 2012. doi: 10.1016/j.proche.2012.06.025.

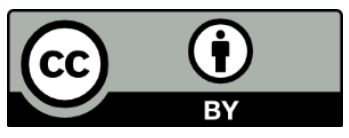

(C) 2018 Authors. Published by the University of Novi Sad, Faculty of Technical Sciences, Department of Graphic Engineering and Design. This article is an open access article distributed under the terms and conditions of the Creative Commons Attribution license 3.0 Serbia (http://creativecommons.org/licenses/by/3.0/rs/). 